Louisiana State University

LSU Digital Commons

Faculty Publications

Department of Oceanography \& Coastal

Sciences

9-1983

Coastal Louisiana Recent Land Loss and Canal Impacts

William W. Scaife

R. Eugune Turner

Robert Constanza

Follow this and additional works at: https://digitalcommons.Isu.edu/oceanography_coastal_pubs 


\section{Coastal Louisiana Recent Land Loss and Canal Impacts}

\section{WILLIAM W. SCAIFE \\ R. EUGENE TURNER' \\ ROBERT COSTANZA}

Center for Wetland Resources

Louisiana State University

Baton Rouge, Louisiana 70803

ABSTRACT / Annual coastal land loss in the sedimentary deltaic plain of southern Louisiana is $102 \mathrm{~km}^{2}$, which is correlated with manmade canal surface area. The relationships between land loss and canals are both direct and indirect and are modified by the deltaic substrate, distance to the coast, and availability of new sediments.
Loss rates are highest in the youngest of the former deltas nearest the coast; they are lowest in the more consolidated sediments far from the coast. The average estimate for land loss at zero canal density in the six regression equations developed was $0.09 \% \pm$ $0.13 \%$ annually, the present land loss rates approach $08 \%$ annually Although additional analyses are needed, we conclude that canals are causally related to a significant portion of the total coastal land loss rates The relation probably involves an interruption of local and regional hydrologic regimes. Reduction of the present acceleration in land loss rates is possible by managing present canals more effectively, by not permitting new ones, and by changing the design of new canals to allow more natural water flow
Louisiana possesses $41 \%$ of the United States' coastal wetlands (Turner and Gosselink 1975). The present coastal land erosion rates, however, are estimated to be 102 $\mathrm{km}^{2} \cdot \mathrm{yr}^{-1}$, or $0.8 \%$ annually (Gagliano and others 1981). These loss rates are extremely high compared with the rest of the United States and have risen geometrically since 1890; elsewhere the loss rates have declined (Gosselink and Baumann 1979; Gagliano and others 1970). Craig and others (1979) discussed some of the general implications of coastal land loss in Louisiana in terms of fisheries, economics, and increased storm damage. The more we learn about the causes and consequences of these losses, the better our understanding of the possible options for managing sedimentary coastlines becomes. A basic problem, therefore, is understanding the causes of the recent increases in erosion rates.

Both natural and man-related factors contribute to coastal land loss in Louisiana. D. Morgan (1977) related shoreline retreat to a relative rise in sea level because of compaction, land subsidence, and actual sea level rise. Earlier, J. Morgan (1963) reported that subsidence and erosion rates follow a decelerating pattern that is dependent on the age of the delta. This implies a natural erosional sequence, with subsequent land loss.

Man contributes to land loss in coastal areas through flood control measures, agricultural practices, and canal construction. Inventories of waterbodies by Gagliano and Van Beek (1975), Adams and others (1976), Barrett (1970), and Chabreck (1972) document the extent of canal dredging in the coastal area. Disregarding the loss of habitat caused by soil dispersal, Gagliano (1973) estimated that canals are responsible for $39 \%$ of a total land loss of $4,435 \mathrm{ha} \cdot \mathrm{yr}^{-1}$. Using this

KEY WORDS: Coastal zone management; Wetlands; Canals; Marshes; Louisiana

'To whom reprint requests should be sent. figure and a canal-to-spoil bank ratio of 1:2.5, Craig and others (1979) estimated that $69 \%$ of total wetland loss can be attributed to canal construction.

Along with the initial loss of land though dredging, canals may contribute to land loss by changing the hydrology of an area. Gagliano (1973) proposed that accelerated erosion results from an increase in tidal prism volume. Stone and others (1978) used a two-dimensional hydrodynamic model created by McHugh (1976) to simulate water flow over a marsh physically disturbed by canals in various alignments. The results showed significant hydrologic change.

Canal densities have increased concurrently with land loss rates in Louisiana. They influence local wetland ecology in ways we are only beginning to appreciate. Understanding such poorly known couplings is important for several reasons. Implicit in the required permitting of canals by the appropriate state and federal agencies is the underlying assumption that canals damage valuable public resources. Many believe, however, that the construction of levees on the Mississippi River and the subsequent loss of sediments offshore are the primary causes of these high land loss rates. Canals are an ancillary, although negative, influence affecting erosion rates in this scheme. We address in this paper the quantitative effect of canals, levees, and other influences (such as a rising sea level) that act separately or together to cause land losses. The results have important implications for developing management schemes to combat erosion (currently being discussed by legislative bodies) and for the correct evaluation of the impacts of canals. New data were recently made available to address the three main purposes of this study: to distinguish between canal-induced and natural land loss and to examine their interaction; to document the relationship between canal density and land loss in the Louisiana coastal region; and, to identify regions where the excavation of canals has had the greatest effect. 
Table 1. Habitat relationships.

\begin{tabular}{|c|c|c|}
\hline Category ${ }^{a}$ & Description & Cowardin habitats included \\
\hline $\begin{array}{l}\mathbf{L} \\
\mathbf{L}\end{array}$ & $\begin{array}{l}\text { Agriculture land } \\
\text { Beach and dune }\end{array}$ & $\begin{array}{l}\text { UDV12 UDV2 UDV2e UDV2x } \\
\text { E1BB2 E2BB2 E2RS2 E2RS2h } \\
\text { E2RS2r M2BB2 R1BB2 R2BB2 } \\
\text { R1RS2h R1RS2r UGR5b }\end{array}$ \\
\hline $\begin{array}{l}\text { L } \\
\text { L, WL } \\
\text { L, WL }\end{array}$ & $\begin{array}{l}\text { Fresh scrub-shrub } \\
\text { Bottomland hardwoods } \\
\text { Brackish marsh }\end{array}$ & $\begin{array}{l}\text { PSS PSS1 PSS12 PSS13 } \\
\text { PF01 PF013 PF034 PF05 } \\
\text { E2EM3P5d E2EM5N5 E2EM5P5 } \\
\text { E2EM5P5d E2EM5P6 E2EM5P6d }\end{array}$ \\
\hline $\begin{array}{l}\text { L, WL } \\
\text { L, WL } \\
\text { L, WL } \\
\text { OW }\end{array}$ & $\begin{array}{l}\text { Mangroves } \\
\text { Fresh marsh } \\
\text { Cypress-tupelo } \\
\text { Fresh aquatic bed }\end{array}$ & $\begin{array}{l}\text { E2SS3 } \\
\text { PEM PEMd PEM5 R1AB2 } \\
\text { PF012 PF024 } \\
\text { L2AB L2AB2 L2AB2h L2AB5 } \\
\text { L2AB5h L2AB5x PAB PAB2 } \\
\text { PAB2h PAB2x PAB5 PAB5x } \\
\text { PDV PFL2 R1AB R1AB5 } \\
\text { R2AB5 }\end{array}$ \\
\hline $\begin{array}{l}\text { OW } \\
\text { OW } \\
\text { OW }\end{array}$ & $\begin{array}{l}\text { Nearshore gulf } \\
\text { Rivers, streams, bayous } \\
\text { Estuarine aquatic bed }\end{array}$ & $\begin{array}{l}\text { M10W } \\
\text { R10W R20W R40W } \\
\text { E1AB E1AB1 E1AB12 E1AB2 } \\
\text { E1AB5 E1AB5H }\end{array}$ \\
\hline OW & Flats & $\begin{array}{l}\text { E1FL E2FL E2FL2 E2FL23 } \\
\text { E2FL24 E2FL3 E2FL34 E2RF2 } \\
\text { E2RF2r E2UB34 L2FL3 L2FL34 } \\
\text { M1UB2 M2FL2 R1FL R1FL3 } \\
\text { R2FL }\end{array}$ \\
\hline ow & Canal & $\begin{array}{l}\text { E1AB5o E10Wo E1AB5x E10Wx } \\
\text { R1AB2x R1AB5x R1AB5o R2AB5x } \\
\text { R10Wo R10Wx R20Wo R20Wx } \\
\text { R40Wx }\end{array}$ \\
\hline OW & Fresh open water & $\begin{array}{l}\text { L10W L10Wh L20W L20Wh L20Wx } \\
\text { L20W4 POW POWh POWo POWx } \\
\text { POW4 }\end{array}$ \\
\hline
\end{tabular}

${ }^{2} L$ = land; $W L$ = wetland; $O W$ - open water

\section{Materiais and Methods}

The data base for this study was a detailed inventory of habitats resulting from a habitat mapping study performed by Wicker and others of Coastal Environments, Inc., for the Office of Biological Services, Fish and Wildlife Service, US Department of the Interior. The study, titled "Mississippi deltaic plain region ecological characterization: A habitat mapping study" (Wicker 1980), consists of $46471 / 2 \mathrm{ft}$ quandragle habitat maps for 1955 and 1978 and a user's manual. The surface area of each of the over 100 habitat categories used in the study was measured for each map and recorded on a computer file. The study area is the coastal region of southeastern Louisiana and southern Mississippi. This land area is the result of numerous deltaic sedimentary depositional episodes occurring during the last 7,000 years as the Mississippi River switched back and forth across the coast. The inland boundary for Mississippi is the 15-ft $(5.1-\mathrm{m})$ contour line. A complete description of maps and the measurement of habitat areas may be found in Wicker (1980).

The study area was divided into seven hydrologic units. Habitat types for each period were tabulated by parish, state, and hydrologic unit. The habitat areas were measured using an electronic digitizer and were recorded on computer tape. Wicker's habitat classification is adapted from the US Fish and Wildlife Service's Classification of Wetlands and Deep-Water Habitat of the United States (Cowardin and others 1979) and is described in detail in Wicker (1980).

The original tape was reorganized into a more manageable format using programs incorporated in the SAS User's Guide (1979). The total areas of habitat systems were summed for each hydrological unit and organized into 14 data sets. Each hydrologic unit was assigned two data sets, one for the series of 1950 s maps and one for the series of 1970 s maps. These data sets contained the map number, types of habitats found within 
the mapped area, and an acreage measurement for each habitat type.

For the purpose of this study we used three categories of habitat: open water, land, and wetland. Our habitat categories, as well as those defined by Cowardin and others (1979) and Wicker (1980), are interrelated as shown in Table 1.

Land or wetland loss was based on the difference in acreage between the 1955 maps and the 1978 maps. To check for consistency within the data, the change in land was plotted against the change in water for each map. If there was not a one-to-one ratio between figures, the map was not included in the analysis. Maps containing fewer than 5,000 acres $(2,000$ ha) of land were also omitted from this study. Predominantly urban, suburban, and industrial areas were excluded as well.

To assess the contribution of canals to land loss, natural subsidence and erosional factors were defined and held constant. This was accomplished by assigning two more variables to each observation. Adams and others (1976) stated that there is a general trend of increased subsidence coastward of the Pleistocene terrace. To account for this subsidence, each map was assigned a value from zero to ten depending on its distance from the cost (Figure 1). Such a value allowed for the grouping of similar maps based on their proximity to the Gulf of Mexico.

Other authors have suggested that the subsidence rate of an area is dependent on the age of the delta complex associated with its progradation (J. Morgan 1963). Maps in the study area were therefore assigned a relative age following Frazier's (1967) designation (see Figures 2 and 3). The resulting maps are shown in Figures 4 and 5.

The effect of canals on land loss was described in terms of three variables: the density of canals in 1955, the percent of increase in canals between 1955 and 1978, and canal density in 1978. Canal density in 1955 was taken to be the ratio of total canal area in 1955 to total land area in 1955, multiplied by 100 . The percent of increase in canals was the change in canal area between 1955 and 1978, divided by canal area present in 1955 multiplied by 100 . Canal density in 1978 was measured as the ratio of total canal area in 1978 to total land area in $1978 \times$ 100. Percent of land loss was defined to be the change in land area between 1955 and 1978 divided by total land area in $1955 \times 100$. When an annual percent of loss or increase figure was used, these variables were divided by 23 , which is the interval between 1978 and 1955.

\section{Results and Discussion}

\section{Distance from Coast}

Subsidence generally decreased with distance from coast (Adams and others 1976). Figure 4 illustrates the relationship

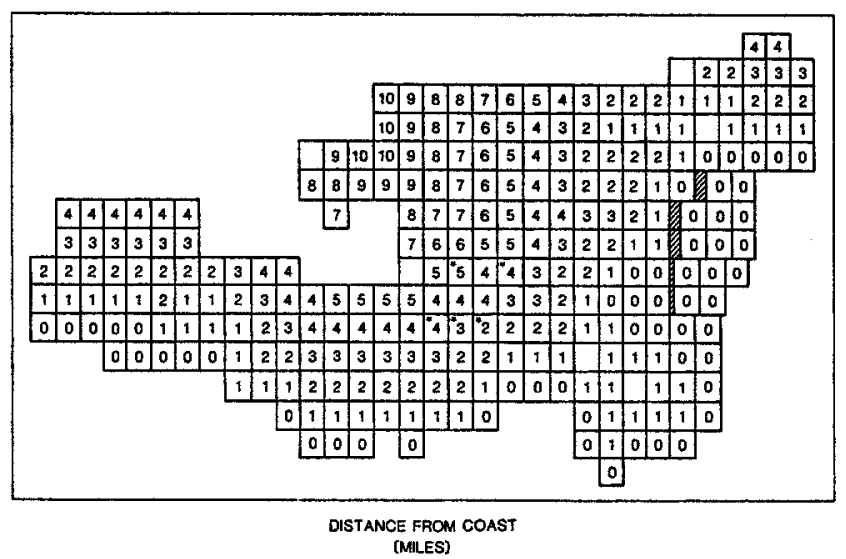

Figure 1. The grid system, composed of $7 \frac{1}{2} \mathrm{ft}$-quadrangle maps, divided into areas according to distance from the coast.

between distance from coast and annual percent of land loss. Median values (indicated by arrows) show a trend of increasing land loss coastward of the surface Pleistocene/Recent contact. Minimum land loss values occur on or close to the Pleistocene terrace. We offer three reasons for this relationship.

First, the net effect of the delta building sequences of the Mississippi River has been to prograde the shoreline of the coastal plain seaward. Underlying sediments deposited near the Pleistocene terrace have necessarily been laid down before sediments in proximity to the Gulf of Mexico. The sediments closer to the surface Pleistocene/Recent contact have had longer to consolidate. These sediments, therefore, tend to have lower subsidence rates and are more resistant to erosion.

Second, as underlying Pleistocene deposits slope seaward, the thickness of the delta sediments increases. Since compaction, dewatering processes, and crustal downwarping are related to overlying sediment load, it follows that subsidence would be greatest where the overlying sediment is thickest. That also occurs in the areas in proximity to the coast.

Third, the seaward margin of the deltas is not only subject to subsidence but also to erosion associated with wave attack and redistribution of sediments. Coleman (1976) described the destruction of the St. Bernard delta and stated that when seaward progradation ceased, subsidence and wave reworking became the dominant processes. Fine-grained material at the ends of the distributary network are resuspended and carried away by littoral currents. Initial shoreline retreat is rapid, but in time the landward retreat caused by wave and current reworking slows appreciably. This explanation accounts not only for greater land loss seaward but also for some of the variation in the coastal margins of the different complexes. 


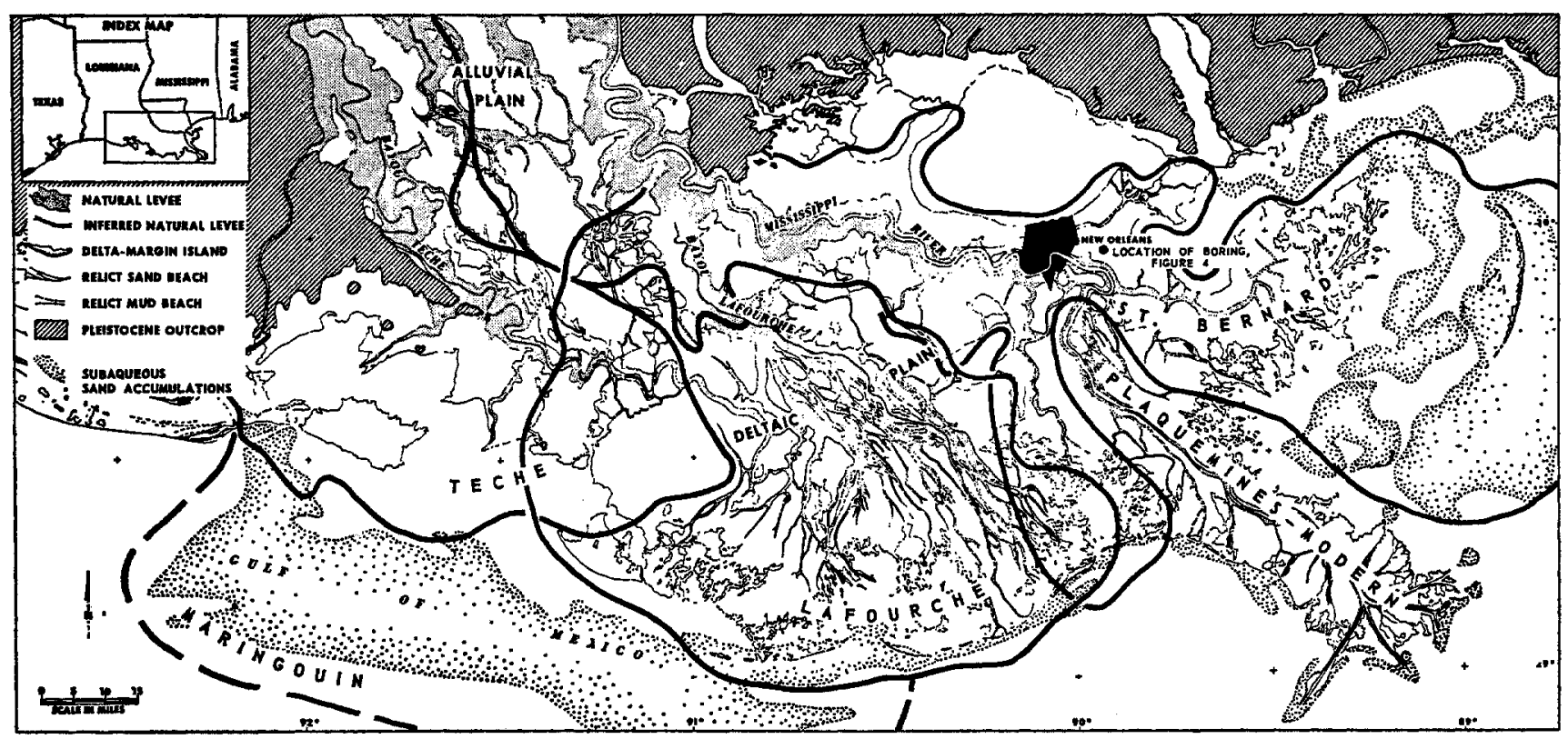

Figure 2. The physiographic features of the Mississippi deltaic plain and the outlines of the major delta complexes (from Frazier 1967).

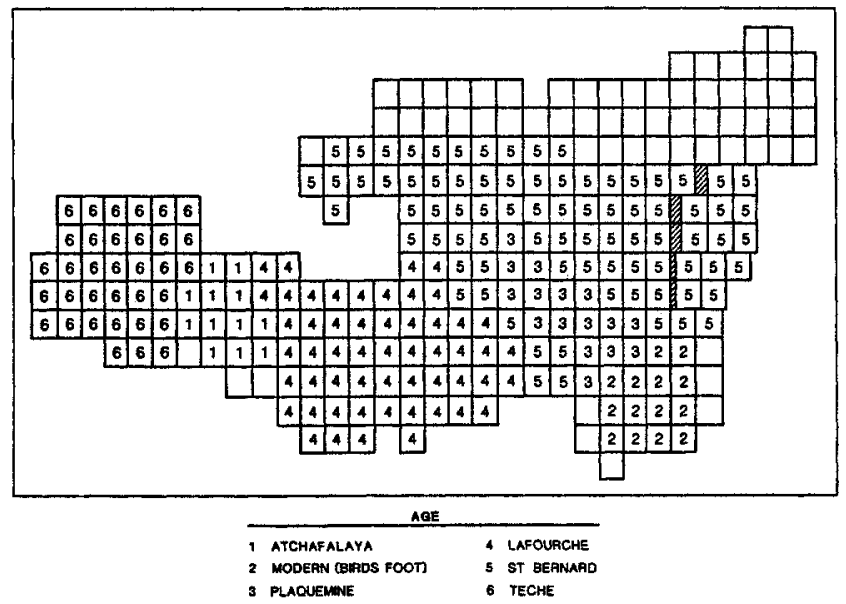

Figure 3. The grid system, composed of $7 \frac{1}{2} \mathrm{ft}$-quadrangle maps, which was divided into areas according to the deltaic substrate material which is of different age. The delta lobes shown here are the same as shown in Figure 2. The area of coastal land comprised of Pleistocene sediments is composed of those blocks above (north) of blocks numbered 5. These latter areas are not deltaic environments, but they are within 3 meters of sea level.

\section{Variation in Land Loss between Delta Complexes}

Variation in land loss rates occurs between abandoned delta systems. J. Morgan (1963) stated: "Rates of subsidence and erosion of abandoned deltas follow a decelerating pattern. Immediately after abandonment, interstitial water losses in sediment are high, as are resulting subsidence rates. As connate fluids are lost, the rate of compaction gradually diminishes as does the rate of subsidence ...". Accordingly, the delta complexes reflect different subsidence rates that are dependent on the time of abandonment.

Our results, as shown in Figure 5, support both J. Morgan (1963) and the projected delta growth and degradation curve of Gagliano (1973). Highest land loss rates occur in the Birdsfoot and Plaquemine deltas. Although the Mississippi River has not actually abandoned the modern delta, flood control and navigational modifications have seriously restricted local sedimentation caused by overbank flooding since the 1950s (D. Morgan 1977). In a functional sense, the river has abandoned some areas in this modern delta.

The older deltas further reflect the decelerating land loss rate with age. Of the degrading deltas, the Teche delta is losing land at the lowest rate, followed by the St. Bernard and Lafourche deltas.

The area around the Atchafalaya delta, which is prograding, is still losing land overall, but this is offset by areas of land building. It should be noted that measurements of land loss 


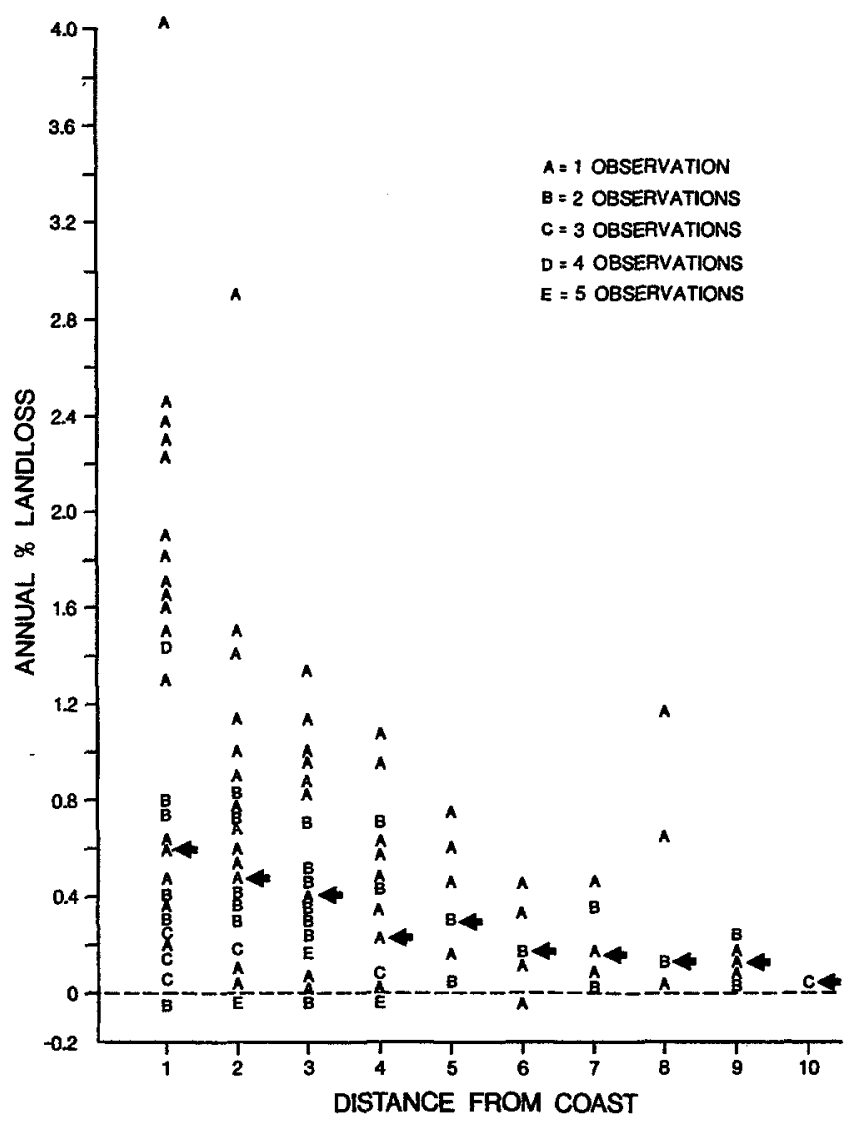

Figure 4. The percent annual land loss for all quadrangle areas in the sample arranged according to their distance from the coast. The arrow demarks the median value for each subset.

rates in the Atchafalaya and birdsfoot deltas may be misleading. Areas in both deltas receive substantial sediment, experience rapid land building, and have land subsidence rates characteristic of subdelta formation. Subdeltas are usually active for periods of 50 to 150 years (Gagliano 1973). Measurements of land loss in an active subdelta may not reflect the trend of the entire delta lobe but only the stage of the prograding-degrading sequence the subdelta occupies.

\section{Relationship of Canal Density and Land Loss}

Land loss was correlated with canal density in maps grouped according to distance from the coast and delta system. Several good correlations were found among most variables; only the best of three canal density estimates are discussed here.

Canal density existing in 1955 was used as the baseline measurement for canals in the study area. A high correlation

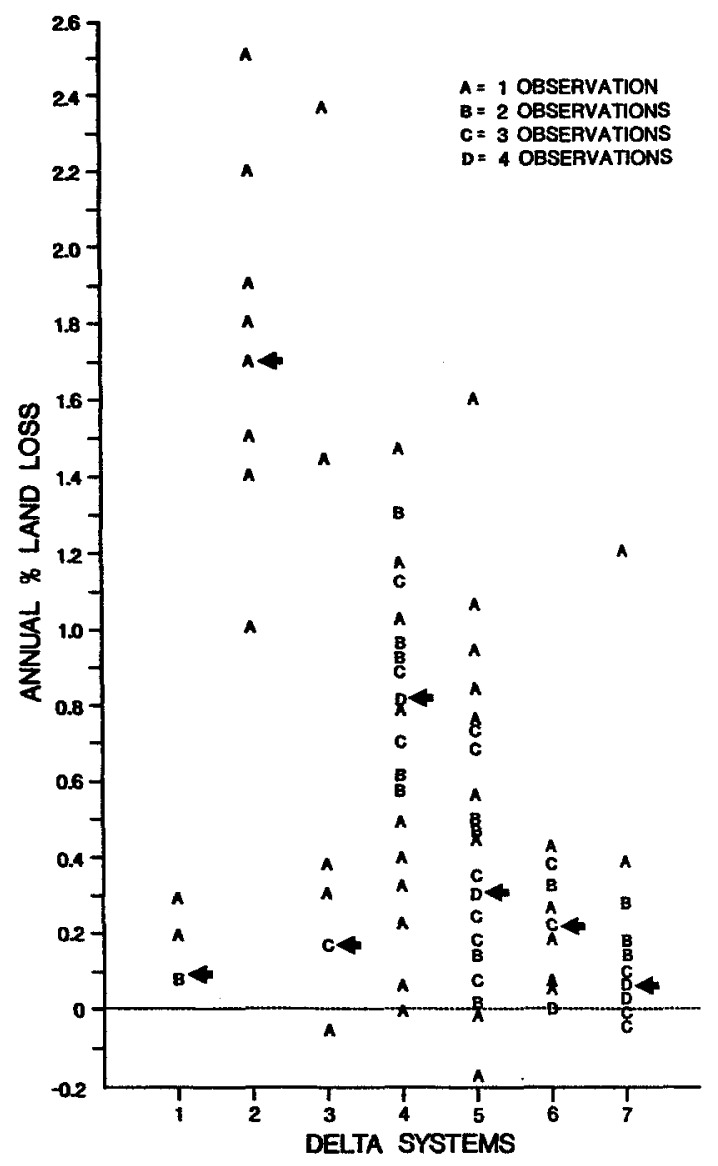

Figure 5. The percent annual land loss for all quadrangle areas in the sample arranged according to the deltaic environment shown in Figure 3. Delta system 1 is the youngest delta (the Atchafalaya); the others are arranged according to age, youngest to oldest, left to right. Number 7 is composed of that coastal land on the Pleistocene terrace. The arrow demarks the median value for each subset.

with this measurement implies that related land loss is primarily caused by post-dredging mechanisms. A low correlation does not necessarily imply that canals are not a factor. An area that had low canal density in 1955 , but which was heavily dredged shortly after the aerial photographs were made, would experience land loss from canals that would not be reflected by the 1955 density estimate.

The percent of increase in canal surface area includes the surface area of canals dredged in the interval between 1955 and 1978, the two years in which maps were made. Canal density in 1978 measures the combined effect of existing canals and those dredged after 1955. However, land loss mechanisms associated with the canals dredged late in the period between 

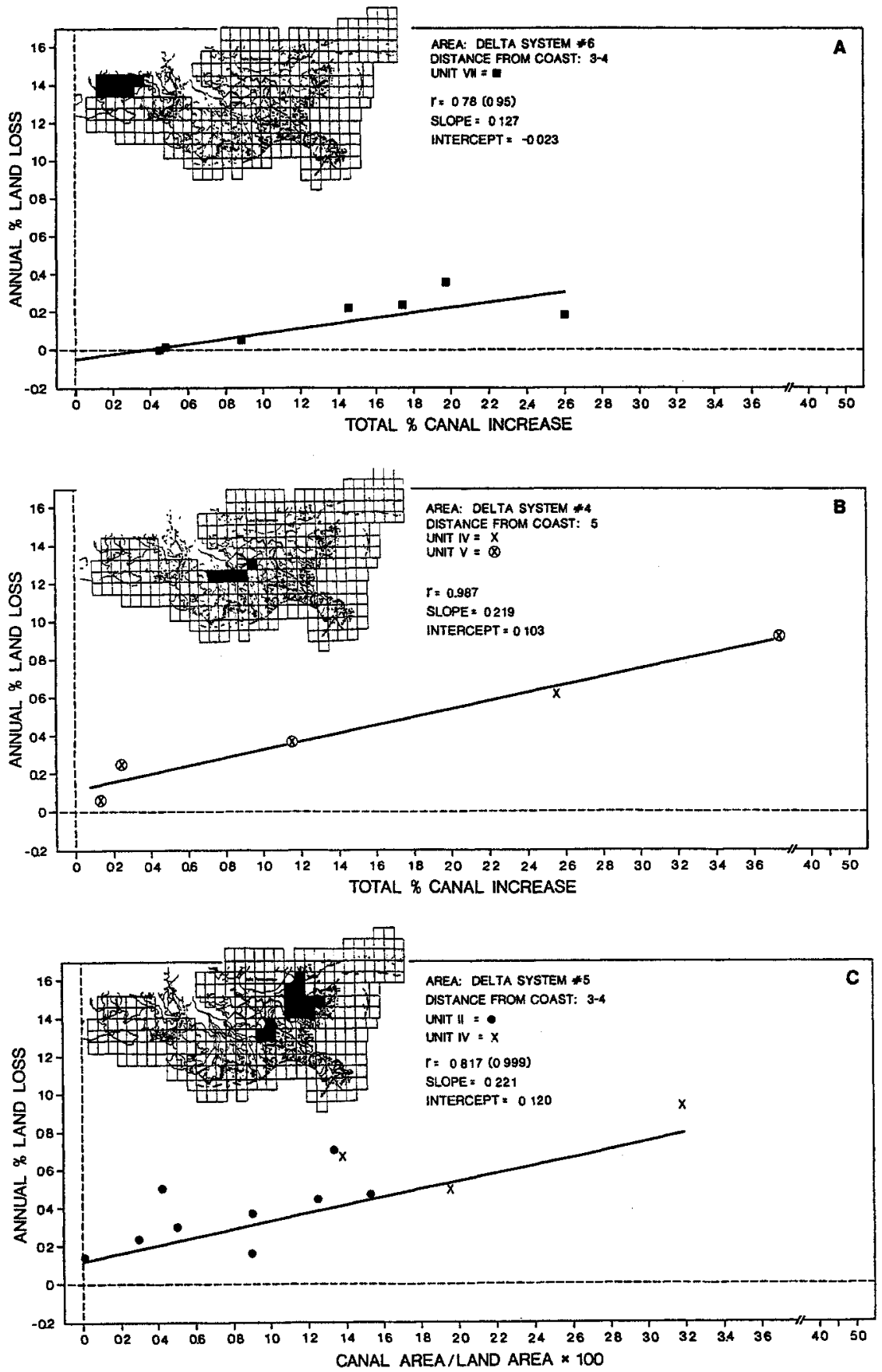

Figure 6. The annual percent land loss in the sample quadrangles shown in the map as a function of various estimates of canals. Different deltaic environments and distances from the coast are shown. (A) Delta system 6; distance 3-4; loss vs. canal increase from 1955 to 1978. (B) Delta system 4, distance 5; loss vs. canal increase from 1955 to 1978 . (C) Delta system 5, distance 3-4; loss vs. canal density in 1955. (D) Delta system 5 , distance $5-7$; loss vs. canal density in 1955. (E) Pleistocene area, distance 1-10; loss vs. canal density in 1978. (F) Delta system 4, distance 1-2; loss vs. canal density in 1978. The correlation coefficient between variables, $r$ and the level of significance of the regression equation $(x)$ is given for each regression together with the slope and intercept.
1955 and 1978 would not have had sufficient time to contribute to land loss rate. In an area such as this, canal density in 1955 would more accurately reflect the land loss associated with canal density. Figures $6(\mathrm{~A})$ through $6(\mathrm{~F})$ are graphs of those maps that showed the most significant correlation between land loss and canal density.
Land loss in the Teche delta complex is highly correlated with the percent of increase in canals dredged three and four miles from the coast (Figure 6(A)). Similarly, in the Lafourche delta complex, land loss can be attributed to percent of increase in canals at five miles from the coast (Figure 6(B)). A comparison of these two graphs gives insight into the interac- 

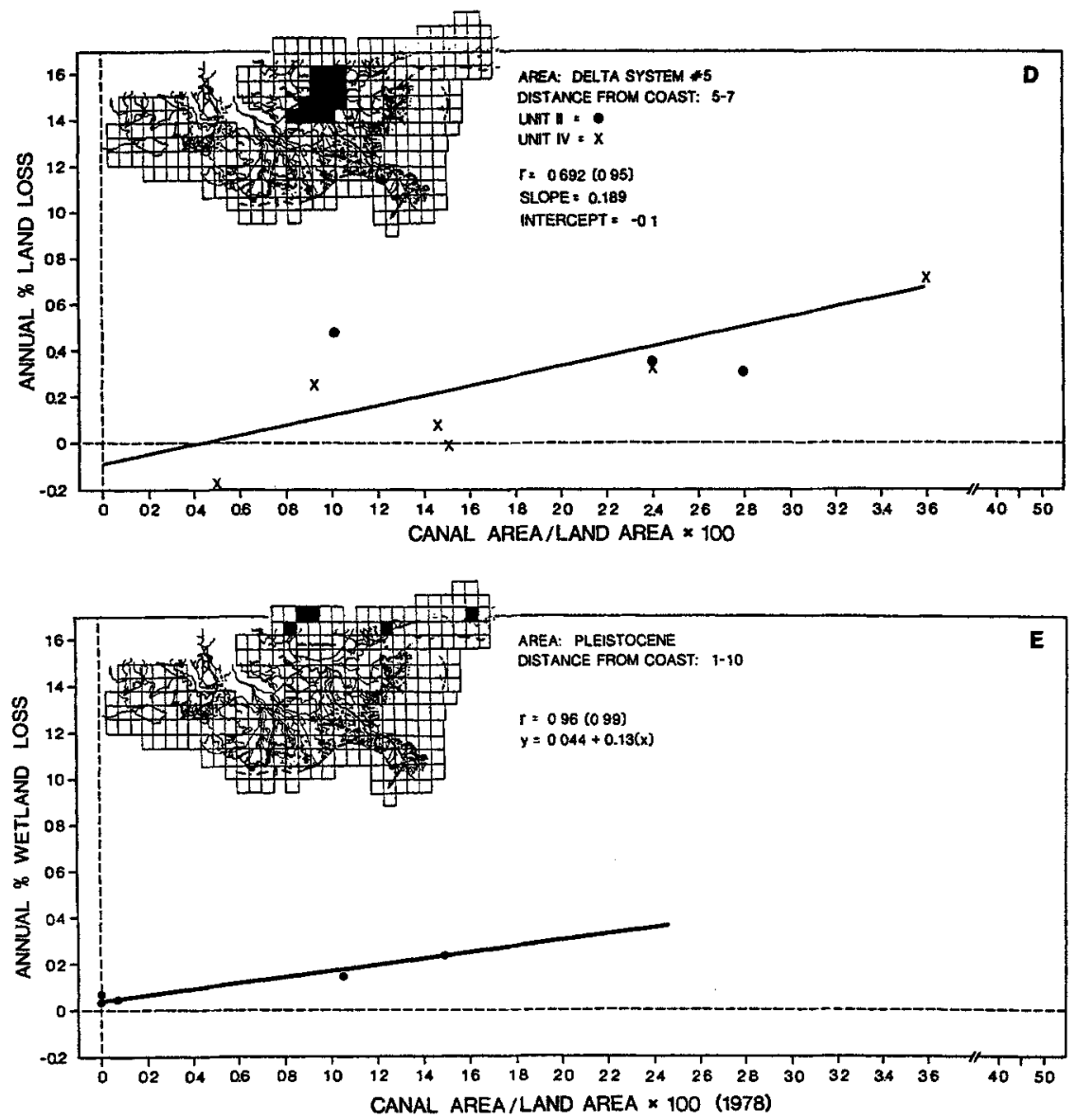

Figure 6. Continued.

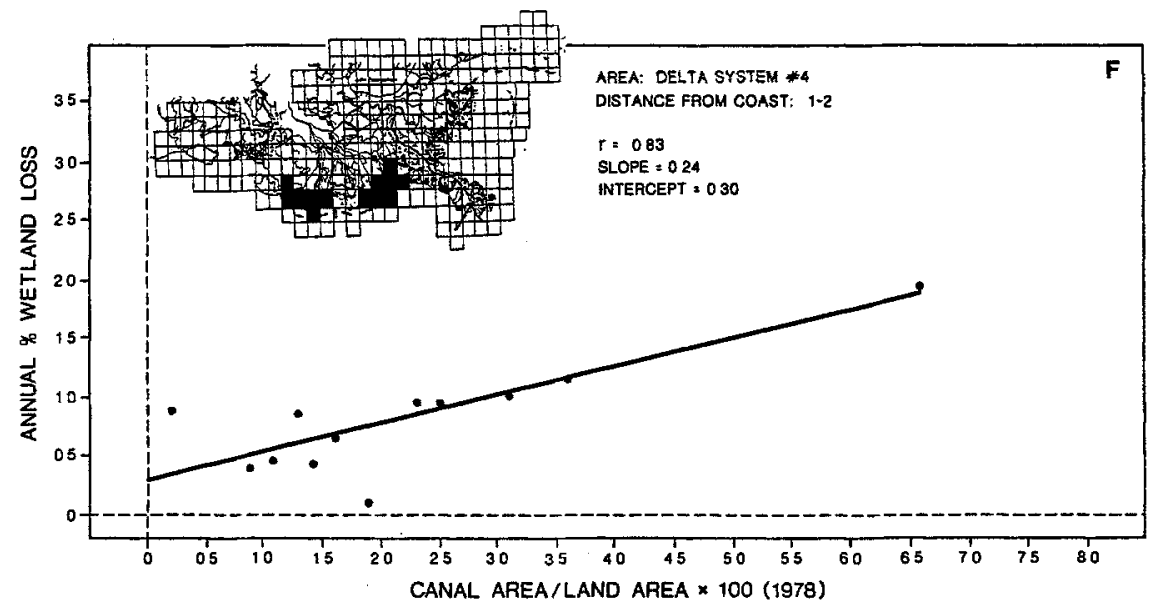

tion between canal-induced land loss and natural land loss. The degree to which land loss is affected by canals is related to the slope of the regression. A large slope indicates a large change in land loss with respect to a small change in canal density.
The slope in Figure $6(\mathrm{~A})$ is smaller than that in Figure 6(B). This implies that canals in areas of the older, more consolidated sediments of the Teche complex do not accelerate land loss as readily as they would in the younger delta sediments of the Lafourche complex. This argument is further 


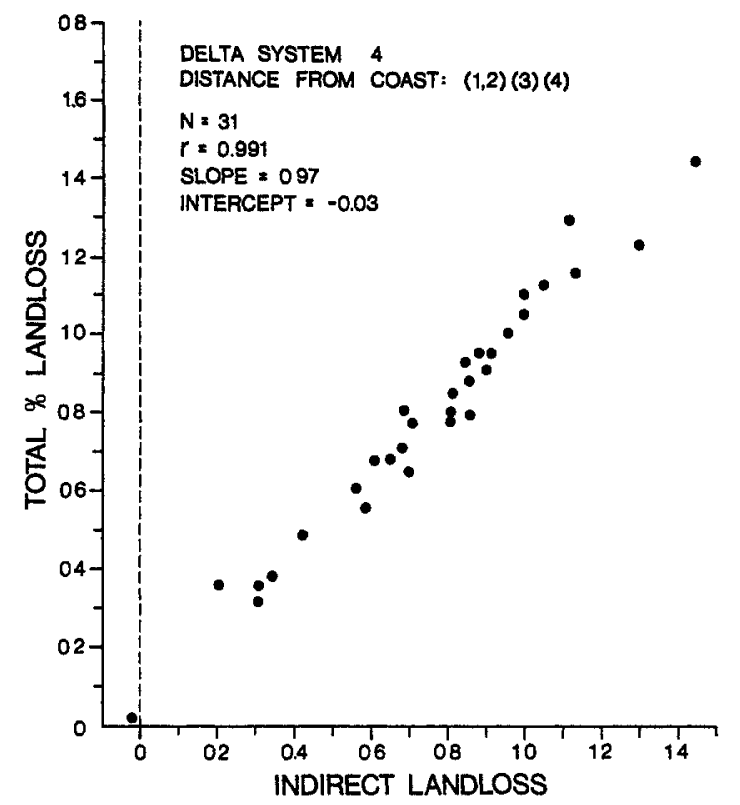

Figure 7. The relationship between the total land loss in each sample area and the indirect (total-direct surface area losses) land losses for Delta system 4, distance 1-4.

substantiated by Figures 6(C) and 6(D). Both areas are in the St. Bernard delta at different distances from the coast. The intercept in Figure $6(\mathrm{C})$ is $0.120 \%$ land loss annually. As a check on the accuracy of this estimate of land loss in the absence of canals, we calculated the average percent of land loss in the St. Bernard delta since its formation. We assumed that it was $100 \%$ land upon formation and that the percent of land declined steadily over the intervening 3,000 years. The historical average was thus estimated to be $0.15 \%$ of land loss annually, or very nearly the intercept (loss rate at zero canal density) obtained in Figure 6(C).

Land farther from the coast is affected less by canals than land closer to the coast. The most conclusive evidence that canal-affected land loss decreases with natural land loss can be seen in estimations of wetlands loss in the Pleistocene (Figure 6(E) ). Only wetland areas were considered in the Pleistocene maps because no correlation could be found between canals and total land loss. Total land includes wetlands, uplands, and other landforms as defined earlier. Canals do not contribute to land loss in the very consolidated sediments of the upland areas other than through the actual physical displacement of land during dredging. In the wetland areas of the Pleistocene, canals are highly correlated with land loss, but the effect, as reflected in the slope, is not as great as that in wetlands in the lower reaches of the Lafourche delta (Figure 6(F)).

\section{Direct Land Loss Caused by Conversion of Land to Water by Canal Dredging}

In 1978, canals in the study area represented 0.85 percent of the total area (land and water); there was an increase of 14,552 ha between 1955 and 1978. Although this represents a sizable amount of land, the direct contribution to total land loss is about $8 \%$ of the total. Figure 7 illustrates the relationship between total percent of land loss and the land loss excluding that caused by canal dredging (the indirect land loss). The approximate one-to-one correspondence implies that the greatest impact of canals is not the direct conversion of land to water but is the result of post-dredging mechanisms.

\section{Conclusions}

The results of this study clearly support the conclusion that canals are a major influence affecting regional variations in land loss rates. The impact of canals appears to be greatest in the younger, abandoned deltas and in areas near the coast. The direct relationship between canal density and land loss rates is true for areas far removed from the influence of the Mississippi River and its levees (Figures 6(A), (B), and (E)). In general, where canal density is high, land losses are high; where land losses are low, canal densities are low. Further, the land loss rates at zero canal density for all six regions shown in Figure 6 average $0.091 \pm 0.139 \%$ annually (mean \pm 1 std. dev.) or about $11 \%$ of the overall land loss rates from 1955 to $1978(0.8 \%$ annually) for the whole coast. The implication is that this annual rate of $0.09 \%$ represents the combined influence of all factors except canals. Canals, therefore, may be responsible for $89 \%$ of the total land losses. There are only three areas not covered in our analysis: the Mississippi River delta; the Atchafalaya delta; and delta region 4, distances 3 and 4. The first two areas are the younger and more dynamic deltas and are areas of land gain instead of loss. The third, delta 4, distances 3 and 4, contains numerous weirs constructed and maintained by a private company. We do not discuss these weirs since they influence wetland hydrology in a manner uncharacteristic of the natural delta area or of canals and thus require special treatment.

A second conclusion is that the indirect influence of canals is far more important than their direct impacts. From 1955 to 1978, canal surface area accounts for less than $10 \%$ of the actual land loss; yet canal density may account for $48 \%$ to $97 \%$ of the statistical variation in regional land loss rates. The influence of canals on coastal erosion rates is therefore a continuing legacy that extends decades beyond the time of their construction.

How is this influence exercised? We have only some partial 


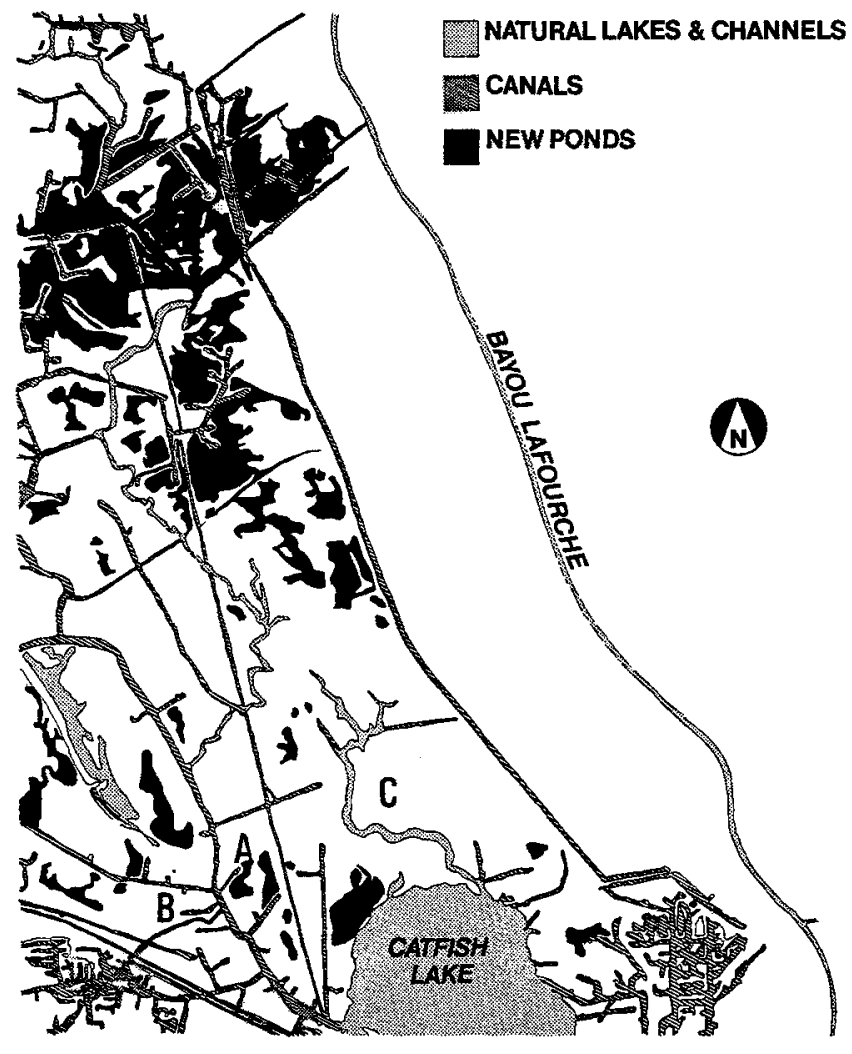

Figure 8. Shown here are the new ponds that formed in the vicinity of Golden Meadow, in southern coastal Louisiana, from 1969 to 1978. Ponds that coalesced eroding lake edges and eroding ponds and streams are not shown. Ponds are in black, canals are striped, and natural lakes and channels are stippled. Note that all the new ponds are in the vicinity of the canals and not near the one natural channel drainage basin draining into the north side of Catfish Lake (marked C; $\mathbf{A}$ and $\mathbf{B}$ are study sites).

answers, but all involve the disruptive influence of canals on coastal hydrology. As the area of canals increases, the area of natural channels decreases logarithmically (Craig and others 1979). Further, almost all canals have a continuous spoilbank levee that must interrupt, if not completely block, sheet flow over the marsh. Canals widen at appreciable rates (Craig and others 1979; Johnson and Gosselink 1982) for hydrologic reasons. Sedimentation rates are highest in streamside, not inland, marshes (Hatton 1980; DeLaune and others 1978). We therefore expect the new erosion "holes" in marshes to be near canals or between them in inland marshes as illustrated in Figure 8. Holes in the marsh that formed between 1969 and 1978 are shown in black. All are located in the area of highest canal density; none are in the region of the one natural channel (some dredging did occur at the shallow tips) located in the middle of the figure, just north of Catfish Lake.

The mitigation of canal impacts must, therefore, either involve a restriction on the construction of new canals or modification of their present hydrologic impact. The first option has not been popular. Of the first two thousand permit applications for canal dredging submitted to the Coastal Management Section of Louisiana's Department of Natural Resources in 1981, two were denied, and these were subsequently approved in an appeal. The second choice is to reduce the impact of canals. Alternatives might include the use of weirs, earthen plugs at the end, discontinuous instead of continuous levees, selective filling, and other engineering design or management approaches. There are basically no data, however, for the evaluation of their relative merit in reducing the indirect impacts including the obvious regional impacts (for example, on barrier island erosion rates increasing with an enlarged tidal prism). Thus proposed methods of controlling or diminishing the impacts of existing and new canals could have substantial effects on the overall land loss rate and deserve further investigation.

\section{Acknowledgments}

We thank our colleagues in the Coastal Ecology Laboratory (CEL), Louisiana State University, and the National Coastal Ecosystem Team, US Fish and Wildlife Service, in Slidell, Louisiana. We were stimulated to write this paper for a workship sponsored by the Louisiana Universities Marine Consortium. We thank Karen Westphal for drafting the figures. This is CEL publication LSU-CEL-82-15. The authors and the US Government reserve the right to reproduce this material and to distribute reprints for informational purposes, notwithstanding any copyright notation that may appear hereon.

\section{Literature Cited}

Adams, R. D., B. B. Barrett, J. H. Blackmon, B. W. Gane, and W. G. McIntire. 1976. Barataria Basin: Geologic process and framework. Louisiana State University Center for Wetland Resources, Sea Grant Publ. No. LSU-T-76-006, Baton Rouge, LA.

Barrett, B. 1970. Water measurements of coastal Louisiana. La. Wildl. and Fish. Comm., U.S. Dept. of Interior Fish and Wildl. Serv., Bur of Comm. Fisheries Project 2-22-T, P.L. 88-309.

Chabreck, R. 1972. Vegetation, water, and soil characteristics of the Louisiana coastal region. La. Agri. Exp. Sta., AEA Inform. Ser. No. 25, Baton Rouge, LA.

Coleman, J. M. 1976. Deltas: Processes of deposition and models for exploration. Continuing Education Publication Company, Inc., Champaign, IL. 
Cowardin, L. M., F. C. Golet, and E. T. LaRoe. 1979. Classification of wetlands and deep-water habitats of the United States. US Fish Wildl. Serv. Biological Services Program FWS/OBS-79/31. 103 pp.

Craig, N. J., R. E. Turner, and J. W. Day, Jr. 1979. Land loss in coastal Louisiana (U.S.A.) and their consequences in coastal Louisiana. Environ. Manage. 3:133-144.

DeLaune, R. D., W. H. Patrick, Jr., and R. J. Buresh. 1978. Sedimentation rates determined by ${ }^{137} \mathrm{Cs}$ dating in a rapidly accreting salt marsh. Nature 275:532-533.

Frazier, D. E. 1967. Recent deltaic deposits of the Mississippi River, their development and chronology. Gulf Coast Assoc. Geol. Soc. Trans. 17:287-315.

Gagliano, S. M. 1973. Canals, dredging, and land reclamation in the Louisiana coastal zone. Hydrologic and Geologic Studies of Coastal Louisiana, Rept. No. 14. Coastal Resources Unit. Center for Wetland Resources, Louisiana State University, Baton Rouge, LA.

Gagliano, S. M., H. J. Kwon, and J. L. Van Beek. 1970. Deterioration and restoration of coastal wetlands. Proc. 12th Coastal Engr. Conf. 3:1767-1781. 1970b. Salinity regimes in Louisiana estuaries. Hydrol. and Geol. Studies of Coastal Louisiana, Rept. No. 2. Coastal Resources Unit, Center for Wetland Resources, Louisiana State Univ., Baton Rouge, LA.

Gagliano, S. M., K. J. Meyer-Arendt, and K. M. Wicker. 1981. Land loss in the Mississippi River Deltaic Plain. Trans. Gulf Coast Ass. Geol. Soc. 31:295-300.

Gagliano, S. M., and J. L. Van Beek. 1975. An approach to multiuse management in the Mississippi delta system. In M. L. Broussard, ed. Deltas, Models for Exploration. Houston Geol. Soc.

Gosselink, J. P. and R. H. Baumann. 1980. Wetland Inventories: Wetland loss along the United States coast. Z. Geomorphol. N.F. 34:173-187.

Hatton. 1980. Aspects of marsh accretion and geochemistry: Barataria Basin, La. M.S. Thesis, Department of Marine Sciences, Louisiana State University, Baton Rouge, LA. 70803.117 pp.

Johnson, W. B., and J. G. Gosselink. 1982. Wetland loss directly associated with canal dredging in the Louisiana coastal zone. In $\mathrm{D}$. Boesch (ed.) Proc. Land Loss Conf., Oct. 1981, Baton Rouge, LA (in press).

McHugh, G. F. 1976. Development of a hydrodynamic numerical model for use in a shallow well-mixed estuary. Sea Grant Publication No. LSU-T-76-008. Center for Wetland Resources, Louisiana State University, Baton Rouge, LA.

Morgan, D. J. 1977. The Mississippi River delta legal-geomorphological evaluation of historic shoreline changes. Geosciences and Man, Vol. XLL. School of Geosciences, Louisiana State University.

Morgan, J. P. 1963. Louisiana's changing shoreline. Baton Rouge, Louisiana State University, Coastal Studies Inst., Tech. Rept. 16, Pt. D, 13 pp.

SAS User's Guide. 1979. SAS Inst. Inc. Raleigh, NC. 494 pp.

Stone, J. H., L. M. Bahr, and J. W. Day, Jr. 1978. Effects of canals on freshwater marshes in coastal Louisiana and implications for management in Good, Whigham, and Simpson, eds. Freshwater
Wetlands: Ecological Processes and Management Potential. Academic Press, New York, NY Pages 299-320.

Turner, R. E., and J. G. Gosselink. 1975. A note on standing crops of Spartina alterniflora in Texas and Florida. Contr. Mar. Sci. 19:113-118.

Wicker, K. M. 1980. Mississippi deltaic plain region ecological characterization: a habitat mapping study. A user's guide to the habitat maps. U.S. Fish and Wildlife Service, Office of Biological Services. FWS/OBS-79-07 and 464 maps. 